\title{
Associations between Public Transit Usage and Bikesharing Behaviors in The United States
}

\author{
Yuanyuan Zhang ${ }^{1,2}$ (D) and Yuming Zhang ${ }^{1, *}$ \\ 1 School of Management, Shandong University, Jinan 250100, China; \\ sduyyzhang@163.com or yzhang2@stern.nyu.edu \\ 2 Stern School of Business, New York University, New York, NY 10012, USA \\ * Correspondence: sduyzhang@gmail.com
}

Received: 2 May 2018; Accepted: 1 June 2018; Published: 4 June 2018

\begin{abstract}
Public bikesharing systems have rapidly expanded across many cities in the United States (US). Previous studies in the literature found that, in general, bikesharing is associated with public transit ridership. However, the interdependencies between public transit usage and bikesharing behaviors have been mixed and have not been fully understood. Therefore, the objective of this research is to examine the associations between the frequency of public transit usage and the probability and frequency of bikesharing usage in the US using data from the 2017 National Household Travel Survey. The respondents were asked how many times they had used public transit and bikesharing in the last 30 days. Zero-inflated negative binomial regression models were conducted to assess the associations between the frequency of public transit usage and the probability and frequency of bikesharing usage. The results show that, in general, a one-unit increase in the frequency of public transit usage is significantly associated with a $4.0 \%$ increase in the probability of bikesharing usage and a $1.4 \%$ increase in the frequency of bikesharing usage. The significantly positive relationship between the frequency of public transit usage and the frequency of bikesharing usage is more pronounced among those living in areas with higher population density or with rail service. The empirical results demonstrate that public transit usage is significantly positively associated with bikesharing usage, and suggest policy implications that improving public transit usage tends to increase the usage of bikesharing. This study also provides significant empirical evidence for the formulation of interventions and policies targeting to promote integrated transportation systems that support multimodal transportation and mutually sustainable transport networks.
\end{abstract}

Keywords: bikesharing; public transit; 2017 NHTS; US; ZINB model

\section{Introduction}

Bikesharing systems are also called public bicycle systems, in which bicycles are available at docking stations that are located throughout a city for shared use. The systems provide publicly available bicycles to customers for temporary rental and allow for users to borrow a bicycle from any nearby station and to return it to another station with an available dock belonging to the system. Bikesharing programs have existed for more than 50 years since the first program in 1965 in Amsterdam [1]. Due to the development of IT and mobile IT devices, bikesharing systems have rapidly expanded throughout the world over the last decade [2,3]. Contemporary bikesharing systems include technologies that allow for scheme operators to track the movements of all the bicycles with integrated global positioning system (GPS) throughout the network.

Bikesharing programs have numerous benefits, offering flexible mobility by providing alternatives to active transportation; reducing car usage and emissions; contributing to healthy living and physical activity benefits; reducing the incidence of various diseases (e.g., diabetes and obesity); reducing fuel 
use, total vehicle miles travel and traffic congestion; contributing to individual money savings; and, providing support for multimodal transport connections [1,2,4-8]. The previous studies on bikesharing investigated aspects, such as demand estimation [9,10], rebalancing strategies [11-15], and factors that influence bikesharing usage [16-22].

Previous studies in the literature found that, in general, bikesharing is associated with public transit ridership [23-25]. However, the interdependencies between public transit usage and bikesharing behaviors have been mixed and have not been fully understood. Bikesharing may be associated with public transit ridership in a number of ways. First, a bikesharing system may have a substitute relationship with the existing public transit network. A person can use bikesharing as a substitute for public transit, resulting in a loss of public transit ridership. Second, a bikesharing system may have a complementary relationship with the public transit system. The complementary association may lead to an increase in public transit ridership, which is common in solving the first-mile/last-mile problem [1]. Third, bikesharing could be used for recreational purposes, which would have no impact on public transit usage. For different users or at different times, bikesharing usage could be interrelated with public transit ridership in any of these three ways.

The number of bikesharing systems in the US has steadily increased year over year since 2010 when the first modern bikesharing systems were launched, from four systems with 1600 bikes in 2010 to 55 systems with 42,000 bikes in 2016 [26]. The vast majority of all bikesharing rides are generated by the country's largest systems. The five largest bikesharing systems generate $85 \%$ of all bikesharing trips, which are Citi Bike in New York, Citi Bike in Miami, Divvy in Chicago, Capital Bikeshare in Greater Washington DC, and Hubway in Greater Boston. Figure 1 documents the expansion of bikesharing trips across the US from 2010 to 2016. The introduction of large bikesharing systems in 2013 resulted in the explosive growth of bikesharing ridership: from just 0.32 million (M) trips in 2010 and 4.5 million trips in 2012, to 13 million trips in 2013 and over 28 million trips in 2016.

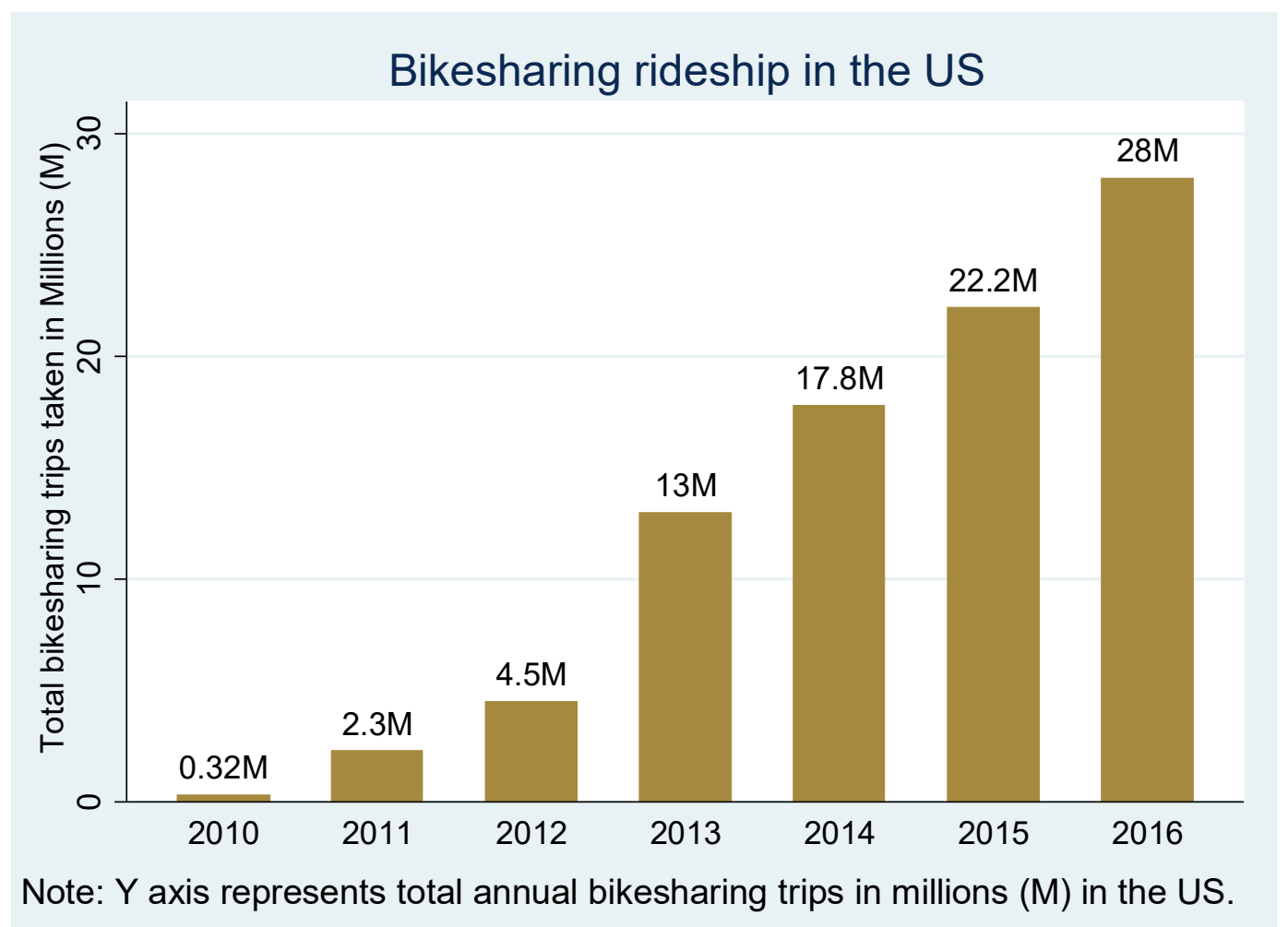

Figure 1. Expansion of bikesharing trips in the US from 2010 to 2016 (The data used in this figure are from NACTO (https: / / nacto.org/bike-share-statistics-2016/)). 
However, it remains unclear how bikesharing is associated with public transit usage. Previous studies used the data from particular cities or systems [23-25] to understand the associations between bikesharing and public transit usage, and did not consider the characteristics of those who rarely or never used the bikesharing service. The objective of this research is to examine the associations between the frequency of public transit usage (FPTU, the number of times of respondent's public transit usage in the last 30 days) and probability of bikesharing usage (PBSU, whether the respondent has used at least once or never used bikesharing in the last 30 days) and frequency of bikesharing usage (FBSU, the number of times of respondent's bikesharing usage in the last 30 days) in the US using the 2017 National Household Travel Survey (NHTS) data, in which the respondents were asked how many times they had used public transit and bikesharing in the last 30 days. Zero-inflated negative binomial regression models (ZINB) were used to assess the associations between FPTU and PBSU and FBSU. The results show that, in general, a one-unit increase in FPTU is significantly associated with a $4.0 \%$ increase in PBSU and a 1.4\% increase in FBSU. Empirical results demonstrate that public transit usage is significantly positively associated with bikesharing usage and suggest the policy implications that improving public transit usage tends to increase the usage of bikesharing. This study also provides significant empirical evidence for the formulation of interventions and policies targeting to promote integrated transportation systems that support multimodal transportation and mutually sustainable transport networks.

The rest of the paper is organized as follows. Section 2 offers a brief review of previous studies on associations between public transit and bikesharing. In the third section, we describe the data that was used in this analysis. Section 4 presents the methodology, and results are provided in the fifth section, followed by the discussion of the model estimation results in the sixth section. Finally, we conclude in the last section.

\section{Literature Review}

There are three possible relationships between bikesharing and public transit: complementary relationship, substitution relationship, or no relationship [24]. Ricci [27] notes that many researchers have paid attention to understanding the modal shift from public transit to bikesharing and the findings regarding how much bikesharing may shift people away from public transit are mixed. Numerous studies have found that bikesharing usage can be predicted by variables relating to public transit ridership [19,28-31]. A limited number of studies have examined the associations between bikesharing and public transit. We have found several most relevant studies on these themes and discussed them in detail in the following paragraphs.

Concerning the complementary situation, bikesharing operators locate stations and infrastructure near public transit stops in order to facilitate conjunction between these two transport modes [2]. Bikesharing systems set bicycles at locations next to public transit stations to offer efficient solutions to complete first-mile/last-mile connections to public transit networks [1] and reduce pressure on expanding public transit services [32,33]. Noland et al. [33] found that, in New York City, the bikesharing usage was higher in the bikesharing stations that were located next to subway stations with a high frequency of average monthly subway ridership. Using regression analysis, Ma et al. [32] found that a $10 \%$ increase in Capital Bikeshare ridership was interrelated with a $2.8 \%$ increase in Metrorail trips. A strong relationship was found between bikesharing docking station trips and train station boardings in Melbourne, Australia, and this relationship was most pronounced during peak hour periods [34]. In Jiangyin, China, $42 \%$ of bikesharing trips were found to be connected to public transit stations [35]. In addition, Yang et al. [36] found that in Beijing, China, 58.4\% of people reported that they combined metro systems with bikesharing programs, while the number was $55 \%$ in Shanghai, China.

The substitution situation refers to trips made by bikesharing that were previously made by public transit [2]. Bikesharing provides an affordable alternative to public transit for short-distance trips, particularly during the peak hour when bikesharing may move faster than public transit systems 
within dense transportation networks. In bikesharing member surveys, many people report that they will reduce their public transit usage as a result of bikesharing, although the effect sizes may vary across cities and even within a city [37-41]. In London, 35\% of bikesharing users report that they shift away from underground rail systems to bikesharing usage [42]. Murphy and Usher [41] conducted a survey and found that, in Dublin, Ireland, $34.6 \%$ of the respondents use bikesharing as a substitute for public transit. Fuller et al. [40] found that $3 \%$ of people who did not use bikesharing reported that they would shift to public transit as a result of bikesharing. Martin and Shaheen [23] conducted a survey in several cities in the US (Washington DC, the Twin Cities, Montreal, and Toronto), and found that $17 \%$ to $47 \%$ of respondents reported that they shifted away from bus systems usage to bikesharing usage, while only $2 \%$ to $14 \%$ of the respondents reported that they increased their bus usage as a result of bikesharing. The authors also found that in Washington DC, bikesharing members who live in the urban core areas had a higher possibility of reporting that they decreased their bus systems use as a result of bikesharing, while the respondents who live in the urban periphery areas showed a higher possibility of reporting increases in bus use. Therefore, depending on different circumstances of the travelers and the urban built environments, bikesharing may increase or decrease individuals' public transit usage. Shaheen et al. [38] also pointed out that, most of the respondents used bikesharing as a substitution for bus systems, while some members used bikesharing as a complement to buses.

In the situation with no relationship between the two modes of travel, bikesharing may be used for recreational purposes, which would have no impact on public transit ridership. In Chattanooga, Tennessee, Webster and Cunningham [43] studied individuals' beliefs and attitudes toward bikesharing in order to have a better understanding of the best way to implement bikesharing programs in the city using data from a series of focus groups. The respondents believed that bicycling could be a good form of physical activity, but they would not choose biking as a primary transportation mode.

Table 1 lists several studies that have examined the associations between bikesharing and public transit in different cities and countries. Table 1 shows that the literature relies on different data sources and variables to analyze the relationship between these two transport modes. Previous studies focusing on the associations between bikesharing and public transit relied on bikesharing systems' data, which consider people who use bikesharing, but not those who rarely or never use bikesharing. In addition, the variables that were used in previous studies for examining the interrelationships between two modes are mainly count of trips for bikesharing docking stations and public transit stations, or the modal shift to bikesharing from public transit, there are few studies considering the associations between the number of times of bikesharing usage by individuals and the frequency of public transit usage. This study developed ZINB models to examine the associations between the frequency of public transit usage and the probability and frequency of bikesharing usage using the 2017 NHTS data.

Table 1. Studies and variables used for examining the associations between bikesharing and public transit.

\begin{tabular}{llll}
\hline \multicolumn{1}{c}{ Study } & \multicolumn{1}{c}{ Country/City } & Data Source & Main Variables \\
\hline $\begin{array}{l}\text { Campbell and } \\
\text { Brakewood (2017) [24] }\end{array}$ & US/New York & Station-level data & $\begin{array}{l}\text { Bikesharing docks and daily unlinked bus } \\
\text { station trips }\end{array}$ \\
\hline Noland et al. (2016) [33] & US/New York & Station-level data & $\begin{array}{l}\text { Count of trips for each bikesharing docking station } \\
\text { and monthly subway station ridership data }\end{array}$ \\
\hline $\begin{array}{l}\text { Murphy and Usher } \\
\text { (2015) [41] }\end{array}$ & Ireland/Dublin & Survey & $\begin{array}{l}\text { Whether or not respondent uses bikesharing as } \\
\text { a substitute for public transit }\end{array}$ \\
\hline Ma et al. (2015) [32] & US/Washington DC & Station-level data & $\begin{array}{l}\text { Average daily weekday Metrorail station ridership } \\
\text { and total ridership of all CaBi bikesharing stations }\end{array}$ \\
\hline $\begin{array}{l}\text { Martin and Shaheen } \\
\text { (2014) [23] }\end{array}$ & US/Washington DC and Minneapolis & Survey & $\begin{array}{l}\text { The ordinal variable of bus usage as a result } \\
\text { of bikesharing }\end{array}$ \\
\hline Shaheen et al. (2013) [38] & $\begin{array}{l}\text { US and Canada/Twin Cities, } \\
\text { Washington DC, Montreal and Toronto }\end{array}$ & Survey & $\begin{array}{l}\text { The ordinal variable of bus usage as a result of } \\
\text { bikesharing }\end{array}$ \\
\hline Buck et al. (2013) [39] & US/Washington DC & Survey & $\begin{array}{l}\text { Percent of public transit trips replaced by } \\
\text { bikesharing ridership }\end{array}$ \\
\hline Shaheen et al. (2011) [35] & China/Hangzhou & Survey & $\begin{array}{l}\text { Self-assessment of the impact of bikesharing on } \\
\text { public transit usage (5-point Likert scale) }\end{array}$ \\
\hline
\end{tabular}




\section{Data}

\subsection{Data Source}

The 2017 NHTS is the most recent population-based nationwide survey conducted by the U.S. Department of Transportation (USDOT), which collects information on personal travel behaviors that were undertaken by members of selected households on a randomly assigned survey day [44]. The NHTS provides data on individual and household travel behavior trends linked to economic, demographic, and geographic factors that influence travel decisions and are used to forecast travel demand. The data collection comprised of two phases: a household recruitment survey (phase 1) and a person-level retrieval survey (phase 2). The 2017 NHTS used address-based sampling with mail-back as the primary recruitment survey response mode and the phone or web as secondary response options, while the person-level retrieval survey phase offered both phone and web response options. The data had a weighted household-level response rate of $30.4 \%$ and a person-level response rate of $51.4 \%$, and the overall weighted response rate was $15.6 \%$. The 2017 NHTS, which was conducted from March 2016 to May 2017, included detailed travel data on 264,234 individuals belonging to 129,696 households. The 2017 NHTS collected data on respondent demographic characteristics (gender, age, driver and worker status, etc.) and household socio-economic characteristics (income, number of workers, and housing type/neighborhood characteristics).

In this study, data from nine states in the US (California, Texas, New York, North Carolina, Georgia, South Carolina, Iowa, Florida, and Illinois) were included in our analysis because bikesharing is more popular in these states. 20,925 people in these nine states answered the question of bikesharing usage (how many times have you used bikesharing in the last 30 days). We excluded 3105 people from our analysis because there were missing data on key variables (e.g., the number of times of public transit usage, age, gender, household income level, etc.), leaving 17,824 individuals for analysis. The statistical software STATA 13.1 was used for all of the analyses in this study.

\subsection{Descriptive Analysis of Bikesharing Usage}

Respondents were asked to report the number of times that they had used bikesharing and public transit (e.g., bus travel and rail travel) in the last 30 days. Figure 2 shows that most of the respondents reported that they have not used bikesharing at all or that they have used it only once in the last 30 days. In total, 16,850 (94.54\%) people have not used a bikesharing service in the last 30 days, and 974 $(5.46 \%)$ respondents have used the bikesharing service 1 99 times. Among those who have used bikesharing 1 99 times in the last 30 days, 203 (20.84\%) people have used it once, and the majority have used it no more than five times $(556,57.08 \%)$, meanwhile, 187 (19.20\%) individuals have used it 6 10 times; 161 (16.53\%) individuals have used it 11 20 times; and, 70 (7.19\%) individuals have used bikesharing 21 99 times.

For count outcome, ZINB models were conducted in this study. The sample size is 17,824 , with 16,850 zero counts and 974 non-zero counts for the number of times of bikesharing usage in the last 30 days. A two-sided $p$-value of less than 0.05 was considered to be statistically significant in our study. Statistical power was estimated on the basis of a binomial test with unequal sizes (ratio $=0.0546 / 0.9454$, the proportion of zero counts $/$ the proportion of non-zero counts). In this case, the sample size of 17,824 with a significance level of 0.05 , the statistic power is 1 . So, the sample size of 17,824 is sufficiently large to provide sufficient statistical power.

Figure 3 shows how the average monthly bikesharing usage for each person per month varies by monthly public transit usage. For all of the following figures, part (a) includes those who use bikesharing more than once in the last 30 days, and part (b) includes all of the people in the sample. In general, the monthly frequency of public transit usage is positively associated with individual's average monthly bikesharing ridership. The average monthly bikesharing ridership for all the people in the sample is 0.46 , while for those who have used bikesharing in the last 30 days, the number is 8.36 . 


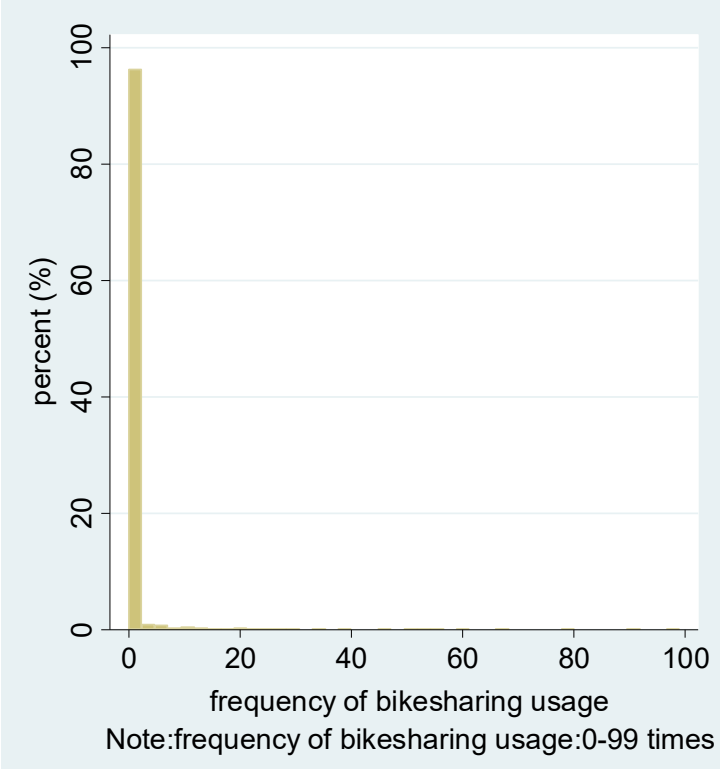

(a)

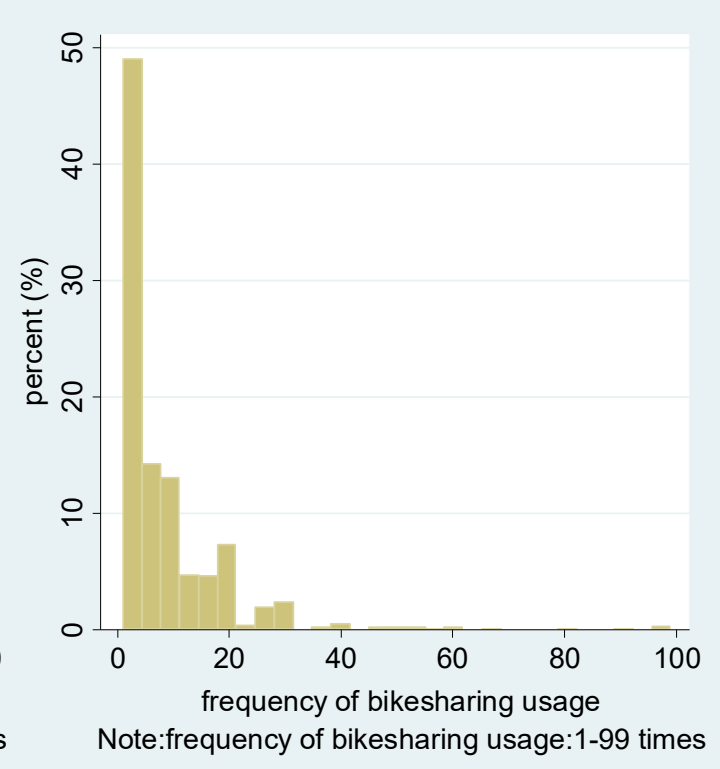

(b)

Figure 2. Frequency distribution of monthly bikesharing usage for those who use bikesharing in the last 30 days: (a) 0 99 times; (b) 1 99 times.

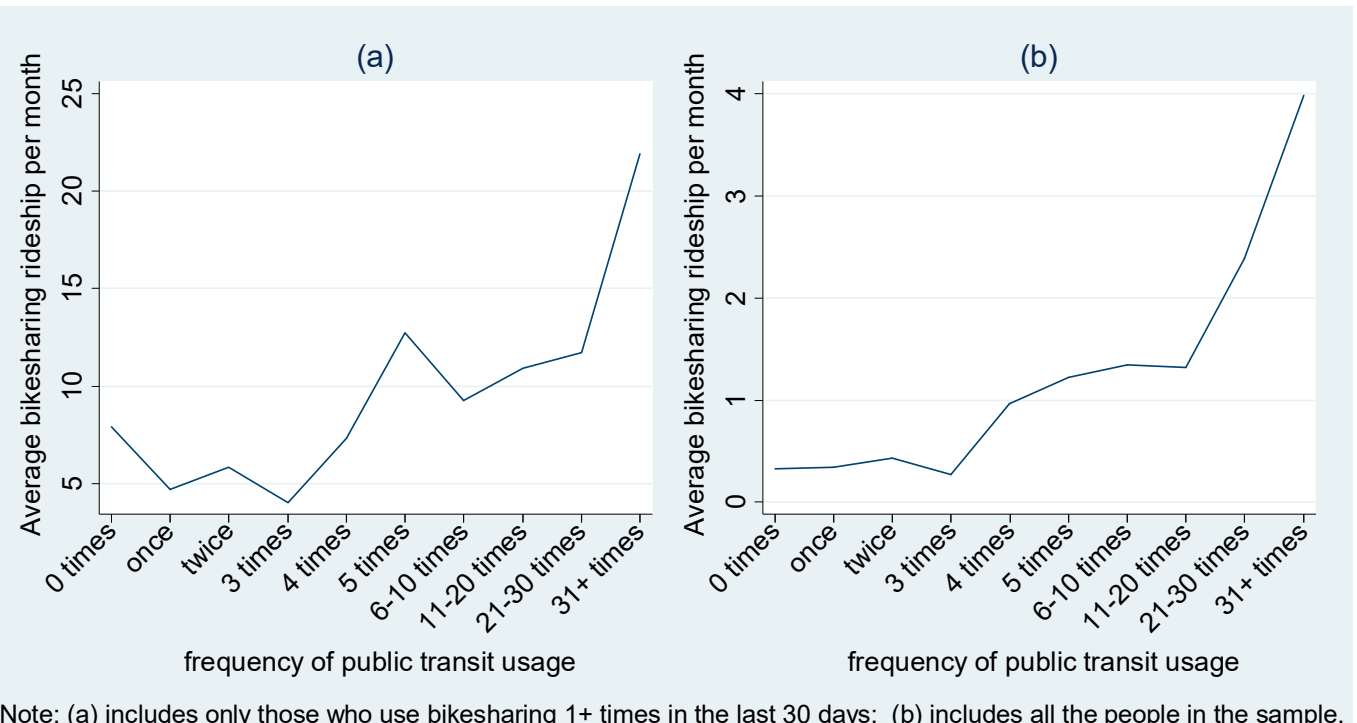

Figure 3. Average monthly bikesharing usage varying by public transit usage for those who use bikesharing in the last 30 days: (a) 1 99 times; (b) 0 99 times.

Figures 4 and 5 show how the associations between bikesharing ridership and public transit usage vary by personal characteristics, including gender, age, education level, race, worker status and driver status. In all of the following figures, the $X$-axis represents the frequency of public transit usage: $0=0$ times, $1=$ once, $2=$ twice, $3=3$ times, $4=4$ times, $5=5$ times, $6=6 \sim 10$ times $7=11 \sim 20$ times, $8=21 \sim 30$ times, $9=31+$ times. On average, men use bikesharing more frequently than women. Very similar patterns for the associations between bikesharing and public transit usage are observed for males and females, white and non-white people, and workers and non-workers, while the relationships are more sensitive to different age groups, education levels and driver status. For the 18 44 age group, bikesharing ridership is positively associated with public transit usage, and those who are under 
17 years old use bikesharing less frequently than people in other age groups do. Individuals with lower education levels use bikesharing more frequently than those with higher education levels. The curve increases rapidly in most cases from value 8 on the $x$-axis shows an obvious positive relationship between public transit usage and bikesharing ridership, indicating that those who have used public transit more than 21 times in the last 30 days use bikesharing more frequently.

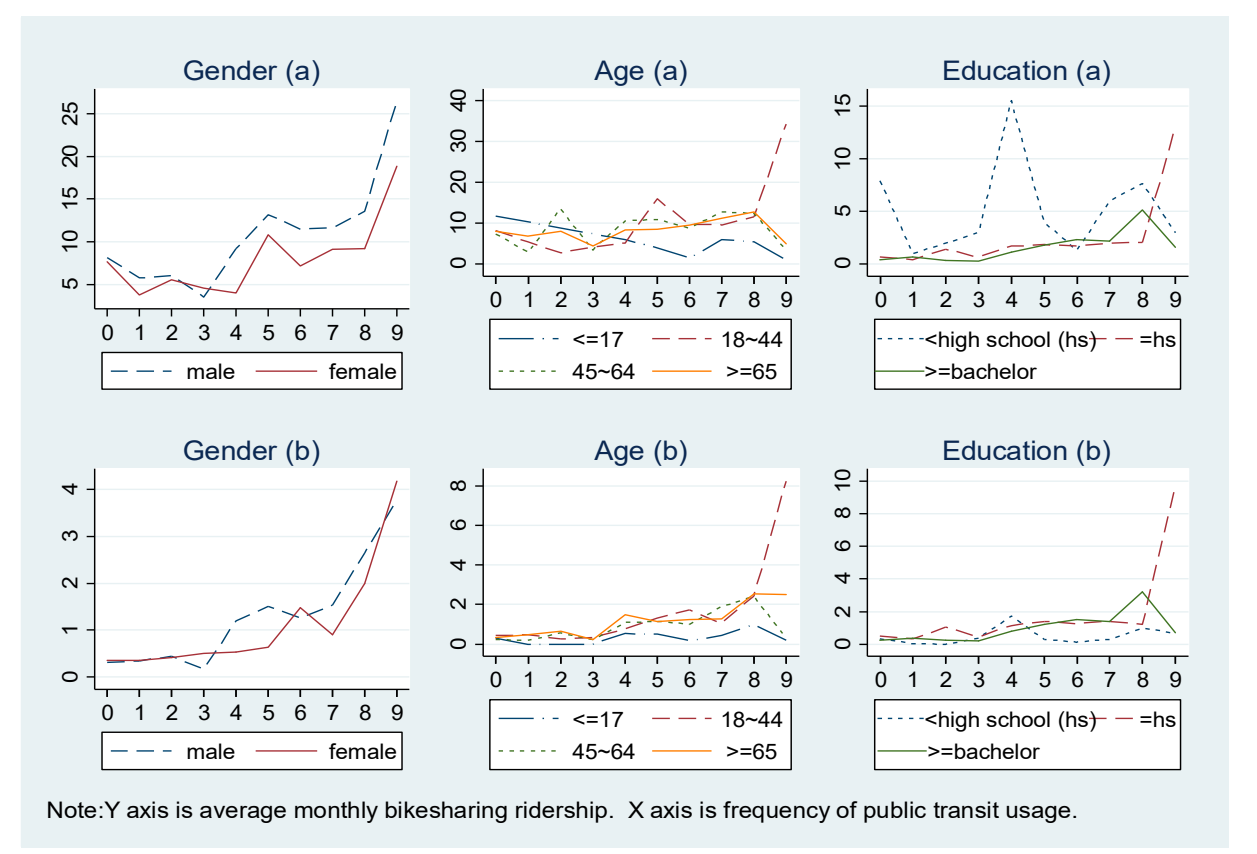

Figure 4. Associations between bikesharing and public transit varying by gender, age, and education level for those who use bikesharing in the last 30 days: (a) 1 99 times; (b) 0 99 times.

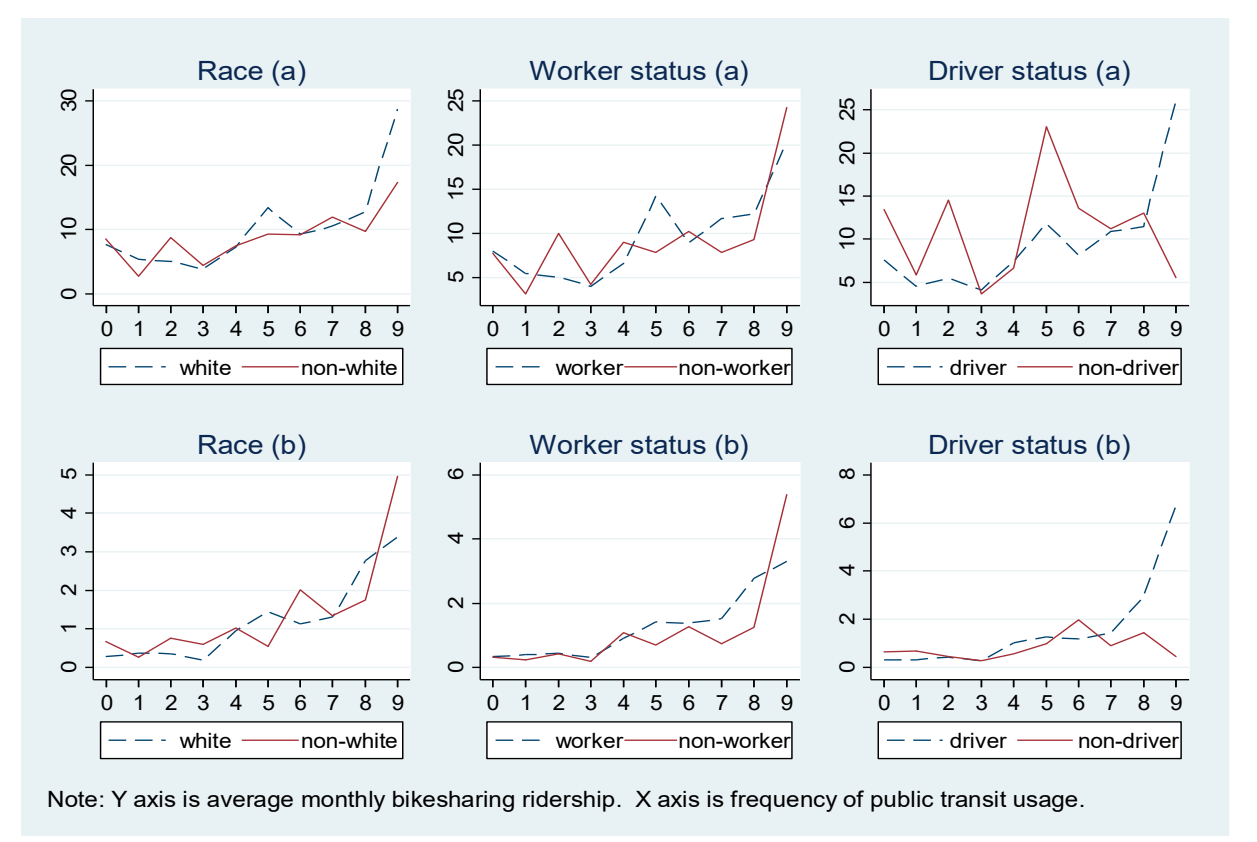

Figure 5. Associations between bikesharing and public transit varying by race, worker, and driver status for those who use bikesharing in the last 30 days: (a) 1 99 times; (b) 0 99 times. 
Figure 6 shows how the associations between bikesharing ridership and public transit usage vary by household characteristics, including annual household income level and count of household vehicles. There are no major differences among households with different income levels. Individuals in households without any vehicles show the highest frequency of bikesharing usage, and also those in households with only one vehicle show a higher frequency of bikesharing usage than those with more than one vehicle. Individuals in households with more than one vehicle show no positive relationships between bikesharing ridership and public transit usage.

Figure 7 shows how the relationships between bikesharing ridership and public transit usage vary by regional characteristics, including population density (persons per square mile at home location), rail service status and urban status. The relationships are similar among different groups, meaning that bikesharing ridership is positively associated with public transit usage within all of the groups. Generally, the higher the population density at the home location, the more frequently individuals would use bikesharing. People who live in areas with heavy rail service also have higher frequency of bikesharing usage than those that are living in areas without heavy rail service.

Figure 8 shows how bikesharing ridership varies by month and how the associations between bikesharing ridership and public transit usage vary by season. The mean number of bikesharing ridership shows that individuals use bikesharing more frequently in summer and fall than in winter and spring. This may be because people feel more comfortable to ride bicycles under the pleasant weather and thus, people are more willing to engage in bikesharing usage under such conditions. Concerning the relationships between two modes, summer and fall show similar trends, while winter and spring show similar trends. In general, individuals who travel in summer or autumn show a higher frequency of bikesharing usage than those who travel in spring or winter do.

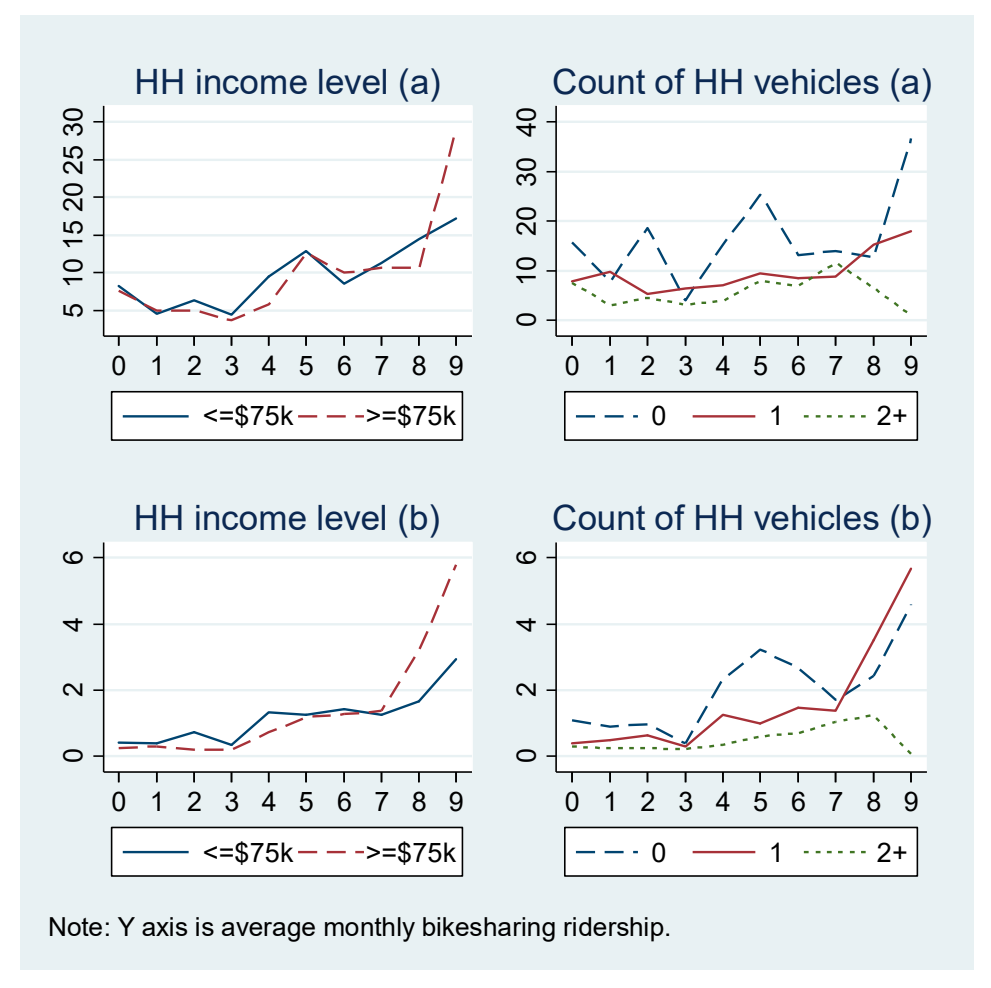

Figure 6. Associations between bikesharing and public transit varying by household characteristics for those who use bikesharing in the last 30 days: (a) 1 99 times; (b) 0 99 times. 


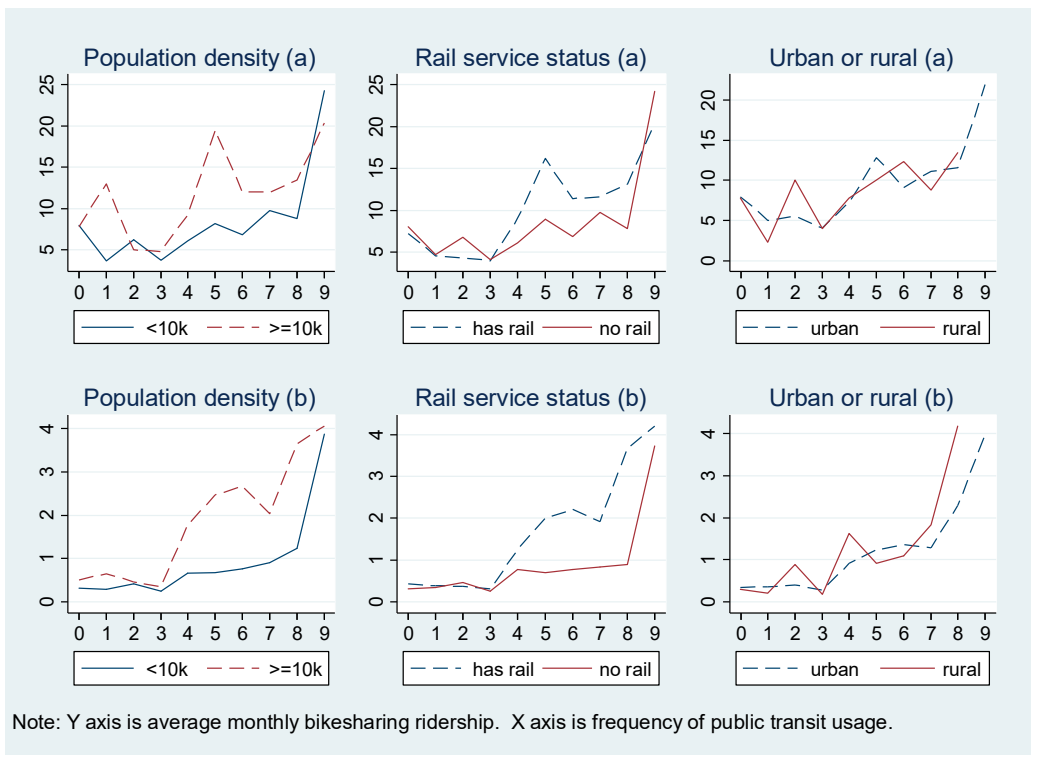

Figure 7. Associations between bikesharing and public transit varying by regional characteristics for those who use bikesharing in the last 30 days: (a) 1 99 times; (b) 0 99 times.

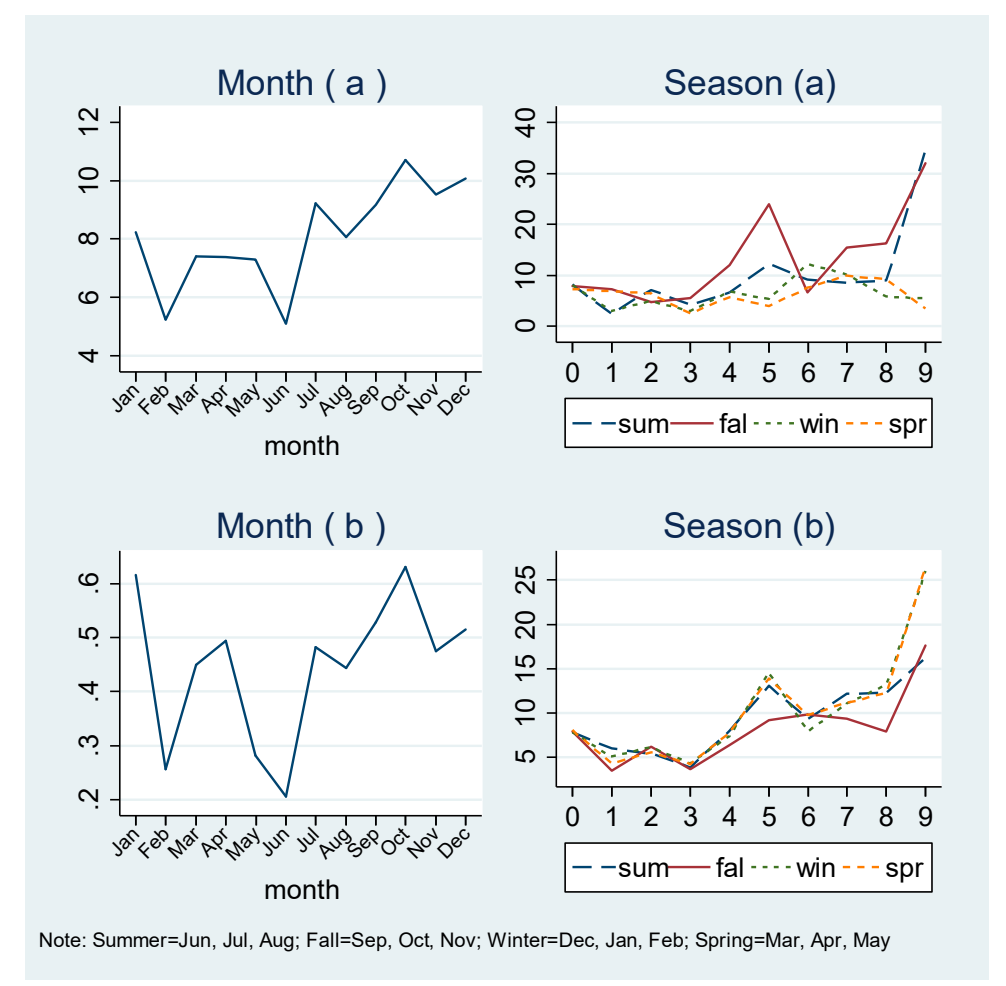

Figure 8. Average monthly bikesharing ridership varying by month and season for those who use bikesharing in the last 30 days: (a) 1 99 times; (b) 0 99 times.

\subsection{Variable Definitions and Descriptive Statistics}

The dependent variable, Bikeshare, is the number of times that a respondent reported that she/he had used bikesharing in the last 30 days. The mean number of bikesharing usage for the whole sample is 0.46 . The main independent variable, Ptused, is the frequency of public transit usage in the last 30 days. The average public transit ridership for each person is 1.60. Variable definitions and their descriptive statistics are shown in Table 2. 
Table 2. Variable definition and descriptive statistics.

\begin{tabular}{|c|c|c|c|c|c|c|}
\hline Variable & Definition & Obs & Mean & Std. Dev. & Min & $\operatorname{Max}$ \\
\hline \multicolumn{7}{|c|}{ Dependent variable } \\
\hline Bikeshare & Frequency of bikesharing usage in the last 30 days & 17,824 & 0.457 & 3.170 & 0 & 99 \\
\hline \multicolumn{7}{|c|}{ Independent variables } \\
\hline Ptused & Count of public transit usage in the last 30 days & 17,824 & 1.602 & 5.656 & 0 & 190 \\
\hline \multicolumn{7}{|c|}{ Individual characteristics } \\
\hline Female & Respondent is female $(\mathrm{Yes}=1, \mathrm{No}=0)$ & 17,824 & 0.385 & 0.487 & 0 & 1 \\
\hline Age & Respondent's age (years) & 17,824 & 48.297 & 16.388 & 16 & 92 \\
\hline Education & $\begin{array}{l}\text { Respondent's education level: } 1=\text { less than high school, } 2=\text { high school } / \text { GED, } 3=\text { some college } / \text { associate, } \\
4=\text { bachelor, } 5=\text { graduate } / \text { professional }\end{array}$ & 17,824 & 3.662 & 1.171 & 1 & 5 \\
\hline White & Respondent's race is white $(\mathrm{Yes}=1, \mathrm{No}=0)$ & 17,824 & 0.843 & 0.364 & 0 & 1 \\
\hline Worker & Respondent is a worker $(\mathrm{Yes}=1, \mathrm{No}=0)$ & 17,824 & 0.655 & 0.475 & 0 & 1 \\
\hline Driver & Respondent is a driver $(\mathrm{Yes}=1, \mathrm{No}=0)$ & 17,824 & 0.925 & 0.264 & 0 & 1 \\
\hline \multicolumn{7}{|c|}{ Household characteristics } \\
\hline HHincome & $\begin{array}{l}\text { Household income level: } 1=\text { less than } \$ 10,000,2=\$ 10,000 \text { to } \$ 14,999,3=\$ 15,000 \text { to } \$ 24,999,4=\$ 25,000 \text { to } \$ 34,999 \text {, } \\
5=\$ 35,000 \text { to } \$ 49,999,6=\$ 50,000 \text { to } \$ 74,999,7=\$ 75,000 \text { to } \$ 99,999,8=\$ 100,000 \text { to } \$ 124,999,9=\$ 125,000 \text { to } \\
\$ 149,999,10=\$ 150,000 \text { to } \$ 199,999,11=\$ 200,000 \text { or more }\end{array}$ & 17,824 & 6.827 & 2.694 & 1 & 11 \\
\hline HHvehcount & Count of household vehicles & 17,824 & 2.214 & 1.236 & 0 & 12 \\
\hline \multicolumn{7}{|c|}{ Geographical characteristics } \\
\hline Pdensity & Population density (persons per square mile) in the census block group of household's home location in log & 17,824 & 7.499 & 1.685 & 3.91 & 10.31 \\
\hline Rail & Home location has heavy rail service $($ Yes $=1, \mathrm{No}=0)$ & 17,824 & 0.166 & 0.372 & 0 & 1 \\
\hline Urban & Household is in an urban area $(\mathrm{Yes}=1, \mathrm{No}=0)$ & 17,824 & 0.828 & 0.378 & 0 & 1 \\
\hline \multicolumn{7}{|l|}{ Season } \\
\hline Spring & The survey was conducted in March, April, or May & 17,824 & 0.179 & 0.383 & 0 & 1 \\
\hline Summer & The survey was conducted in June, July, or August & 17,824 & 0.396 & 0.489 & 0 & 1 \\
\hline Fall & The survey was conducted in September, October, or November & 17,824 & 0.210 & 0.407 & 0 & 1 \\
\hline Winter & The survey was conducted in December, January, or February & 17,824 & 0.216 & 0.411 & 0 & 1 \\
\hline
\end{tabular}


We controlled for four groups of variables that may affect individuals' bikesharing behaviors. First, NHTS provides a wide range of individual characteristics. The demographics of travelers are measured by gender (Female), age (Age), level of education (Education), whether the respondent's race is white (White), whether the respondent is a worker (Worker), and whether the respondent is able to drive (Driver). Second, a respondent's household is characterized by the household income level (HHincome) and count of household vehicles (HHvehcount). Third, the regional characteristics are measured by the population density at the home location (Pdensity), whether there is heavy rail service in the region (Rail), and whether the home is located in an urban area (Urban). Finally, the season (Season) is also considered as a control variable.

\section{Methodology}

\subsection{Model Selection}

In this analysis, the dependent variable was the number of times of bikesharing service usage, which was coded as a discrete non-negative count variable in the dataset. The most appropriate methodological techniques for frequency modeling of count variable as a predicted variable of a statistical model include Poisson regression, negative binomial regression (NB), zero-inflated Poisson regression (ZIP), and zero-inflated negative binomial regression (ZINB) $[45,46]$.

The Poisson regression count model requires that the variance of the data must be approximately equal to the mean; however, the possibility of over-dispersion (meaning that the variance is obviously larger than the mean of the data) may lead to biased, inefficient coefficient estimates [47]. NB regression models are more suitable to be used as the statistical models when the data are over-dispersed [48]. However, the Poisson regression model and the NB model could not address the possibility of zero-inflated problems when the data have excess zero counts for the predicted variable [49]. The ZIP models and ZINB models could account for the zero-inflated counting processes, by dividing the counting processes into two different processes (the true zero-state process and the count-data process) and allowing for factors to affect both processes [50]. The ZIP models have a limitation that the variance and the mean should be equal, while the ZINB models relieve the restriction [50].

The ZINB models are often used in transportation safety research fields [48]. Crash-frequency data are non-negative, discrete count values, and the ZINB model could account for the over-dispersion problem and handle datasets that have excess zero-crash observations [48]. A review of studies on traffic safety shows that the zero-inflated models are more appropriate for the analyses than the other models when the zero counts in the observations are over 65\% [51]. Shen and Neyens [52] conducted ZINB models to examine the relationship between hospital length of stay of teen drivers with the crash-related characteristics, and the zero counts of hospital length of stay are $94.2 \%$ and $96.7 \%$ for male and female teen drivers, respectively. As the data for our analysis are over-dispersed (the variance of bikesharing usage in the last 30 days is significantly greater than the mean) and zero-inflated (zero counts of bikesharing usage in the last 30 days are $94.54 \%$ ), the ZINB model is the best model to fit the data.

\subsection{Zero-Inflated Negative Binomial Regression Model}

The following sections present ZINB distributions, the general forms of the ZINB mixed model, and provide brief descriptions of its application in our analysis.

\subsubsection{ZINB Distribution}

The ZINB models assume that there are two different data generation processes [53,54]. The first process is a zero-count process (zero state, odds of always 0 ) with probability $p$, and the second process is a count process (non-zero state, odds of not always being 0 ) that is governed by an NB with a probability of $(1-p)$, which also generates zero counts in this process. To get the overall probability 
of zero counts, we should combine the probability of zeros from both of the two processes. Thus, with $Y$ denoting the number of times of bikesharing usage, the ZINB distribution [55] could be written as:

$$
\begin{gathered}
P(Y=0)=p+(1-p)\left(\frac{r}{\mu+r}\right)^{r} \\
P(Y=y)=(1-p) \frac{\Gamma(y+r)}{\Gamma(r) \Gamma(y+1)}\left(\frac{r}{\mu+r}\right)^{r}\left(\frac{\mu}{\mu+r}\right)^{y} y=1,2,3, \ldots
\end{gathered}
$$

where $\mu$ is the mean and $r^{-1}$ is the dispersion parameter of the underlying NB distribution. The mean and variance of the ZINB random variable are:

$$
\begin{gathered}
E(Y)=(1-p) \mu \\
\operatorname{Var}(Y)=(1-p)\left(1+\frac{\mu}{r}+p \mu\right) \mu
\end{gathered}
$$

As $r \rightarrow \infty, r^{-1} \rightarrow 0, \operatorname{Var}(Y) \rightarrow(1-p)(1+p \mu) \mu$, the ZINB distribution reduces to the ZIP distribution.

\subsubsection{ZINB Mixed Model}

Let $Y_{i j}\left(i=1,2, \ldots m ; j=1,2, \ldots n_{i}\right.$ and $\sum_{i=1}^{m} n_{i}=n$ represents the total number of observations) be the ZINB distributed random variable of the $j$-th observation in the $i$-th cluster. We can see from Formulas (5) and (6) that, in the regression setting, both $\operatorname{logit}\left(p_{i j}\right)$ and $\log \left(\mu_{i j}\right)$ are assumed to depend on a linear function of covariates. The covariates that appear in these two formulas could be different and they are not necessarily the same. The ZINB mixed model is defined, as follows:

$$
\begin{gathered}
\operatorname{logit}\left(p_{i j}\right)=X_{i j}{ }^{T} \beta+\mu_{i} \\
\log \left(\mu_{i j}\right)=Z_{i j}{ }^{T} \gamma+v_{i}
\end{gathered}
$$

where $X_{i j}$ are the vectors of covariates for the logistic component and $Z_{i j}$ are the vectors of covariates for the NB component; $\beta$ and $\gamma$ are, respectively, the corresponding vectors of coefficients of these two regression models. Let $\mu=\left(\mu_{1}, \ldots, \mu_{m}\right)^{T}$ and $v=\left(v_{1}, \ldots, v_{m}\right)^{T}$. For simplicity, we assumed the random effects $\mu$ and $v$ to be independent and distributed as $N\left(0, \sigma_{\mu}^{2} I_{m}\right)$ and $N\left(0, \sigma_{v}^{2} I_{m}\right)$, respectively, where $I_{m}$ denotes an $m \times m$ identity matrix. For model estimation, we use maximum likelihood methods to estimate the coefficients of the ZINB models.

\subsubsection{Application of ZINB Model}

To achieve the overall goals of this study, we used three ZINB models to estimate the associations between the bikesharing ridership and public transit usage. The zero-inflated problem (large number of zero counts of bikesharing usage in the last 30 days) could potentially be addressed by a two-state process, in which the frequency of bikesharing usage could belong to one of two states: a zero state (odds of always 0 ) and a non-zero state (not always 0 ). For our ZINB regression model, $X_{i j}$ and $Z_{i j}$ are the same. The logistic component (zero state) is used to examine the association between FPTU and PBSU, while the NB component (non-zero state) is used to examine the association between FPTU and FBSU.

\section{Results}

We conducted ZINB models to examine the associations between bikesharing behaviors and public transit usage. Overall, the results indicate a significant positive relationship between bikesharing ridership and public transit usage. Locating bikesharing stations in areas with more residential 
population tends to lead to more bikesharing usage [33], so we conducted ZINB models to examine how the associations between bikesharing and public transit usage vary by population density at home location. Noland et al. [33] found that, in New York City, bikesharing stations that are located near subway stations saw higher bikesharing ridership, so we also conducted ZINB models to examine how the relationship between bikesharing and public transit usage varies by rail service status at home location.

\subsection{Results for Associations between Bikesharing and Public Transit Usage}

Table 3 presents the results from the ZINB model. The marginal effects $\left(e^{\gamma}-1\right)$ in the non-zero state represent the percentage of change in the monthly FBSU for a one-unit change in an independent variable, holding all the other variables constant. A one-unit increase in public transit usage significantly increases a respondent's FBSU by $1.4 \%$, and the result is significant at the $0.05 \%$ level. The marginal effects $\left(e^{\beta}-1\right)$ for the zero state refer to the change in the PBSU for a one-unit change in an independent variable, holding all the other variables constant. A negative marginal effect indicates that the respondent is less likely to have a zero times of bikesharing usage and thus is more likely to use bikesharing at least once in the last 30 days, meaning a higher PBSU. A one-unit increase in public transit usage significantly increases a respondent's PBSU by $4.0 \%$, and the result is significant at the $0.001 \%$ level.

Table 3. ZINB model results (dependent variable: Bikeshare).

\begin{tabular}{|c|c|c|c|c|c|}
\hline Variables & Coef. & Std. Err. & $z$ Value & $p$ Value & Marginal Effects \\
\hline \multicolumn{6}{|c|}{ non-zero state (not always 0 ) } \\
\hline Ptused & 0.014 * & 0.006 & 2.37 & 0.018 & $1.4 \%$ \\
\hline Female & $-0.199 *$ & 0.101 & -1.97 & 0.048 & $-18.0 \%$ \\
\hline Age & 0.002 & 0.003 & 0.69 & 0.488 & $0.2 \%$ \\
\hline Education & -0.067 & 0.048 & -1.37 & 0.169 & $-6.4 \%$ \\
\hline White & 0.008 & 0.117 & 0.07 & 0.947 & $0.8 \%$ \\
\hline Worker & 0.120 & 0.116 & 1.04 & 0.299 & $12.8 \%$ \\
\hline Driver & $-0.400 *$ & 0.183 & -2.18 & 0.029 & $-32.9 \%$ \\
\hline HHincome & 0.003 & 0.020 & 0.16 & 0.872 & $0.3 \%$ \\
\hline HHvehcount & $-0.122 *$ & 0.048 & -2.56 & 0.011 & $-11.5 \%$ \\
\hline Pdensity & -0.008 & 0.043 & -0.19 & 0.848 & $-0.8 \%$ \\
\hline Rail & 0.001 & 0.134 & 0.01 & 0.992 & $0.1 \%$ \\
\hline Urban & 0.046 & 0.191 & 0.24 & 0.811 & $4.7 \%$ \\
\hline Spring & $-0.573^{* * *}$ & 0.161 & -3.55 & 0.000 & $-43.6 \%$ \\
\hline Summer & -0.215 & 0.132 & -1.63 & 0.103 & $-19.3 \%$ \\
\hline Winter & $-0.471^{* *}$ & 0.145 & -3.26 & 0.001 & $-37.6 \%$ \\
\hline Intercept & $2.596^{* * *}$ & 0.375 & 6.92 & 0.000 & \\
\hline \multicolumn{6}{|c|}{ zero state (odds of always 0 ) } \\
\hline Ptused & $-0.041^{* * *}$ & 0.006 & -6.80 & 0.000 & $-4.0 \%$ \\
\hline Female & $-0.260 * * *$ & 0.076 & -3.42 & 0.001 & $-22.9 \%$ \\
\hline Age & 0.003 & 0.002 & 1.20 & 0.232 & $0.3 \%$ \\
\hline Education & 0.084 * & 0.037 & 2.28 & 0.022 & $8.7 \%$ \\
\hline White & $0.522 * * *$ & 0.091 & 5.73 & 0.000 & $68.6 \%$ \\
\hline Worker & $-0.188 *$ & 0.088 & -2.14 & 0.032 & $-17.2 \%$ \\
\hline Driver & $-0.699 * * *$ & 0.150 & -4.67 & 0.000 & $-50.3 \%$ \\
\hline HHincome & $0.072 * * *$ & 0.016 & 4.49 & 0.000 & $7.5 \%$ \\
\hline HHvehcount & 0.074 * & 0.037 & 2.01 & 0.045 & $7.7 \%$ \\
\hline Pdensity & -0.049 & 0.033 & -1.46 & 0.144 & $-4.7 \%$ \\
\hline Rail & $-0.689^{* * *}$ & 0.096 & -7.20 & 0.000 & $-49.8 \%$ \\
\hline Urban & 0.216 & 0.145 & 1.48 & 0.138 & $24.1 \%$ \\
\hline Spring & -0.006 & 0.124 & -0.05 & 0.964 & $-0.6 \%$ \\
\hline Summer & -0.086 & 0.099 & -0.88 & 0.381 & $-8.3 \%$ \\
\hline Winter & $-0.267^{*}$ & 0.111 & -2.41 & 0.016 & $-23.4 \%$ \\
\hline Intercept & $2.299^{* * *}$ & 0.296 & 7.78 & 0.000 & \\
\hline \multicolumn{2}{|c|}{ Number of obs } & \multicolumn{2}{|c|}{17,824} & & \\
\hline \multicolumn{2}{|c|}{ Nonzero obs } & \multicolumn{2}{|c|}{974} & & \\
\hline \multicolumn{2}{|c|}{ Zero obs } & \multicolumn{2}{|c|}{16,850} & & \\
\hline \multicolumn{2}{|c|}{ Log likelihood } & \multicolumn{2}{|c|}{-6478.468} & & \\
\hline \multicolumn{2}{|c|}{ LR chi2 } & \multicolumn{2}{|c|}{$54.35^{* * *}$} & & \\
\hline
\end{tabular}


Table 3 also shows the results for the control variables. Women are $22.9 \%$ more likely to use bikesharing, but they use it $18 \%$ less frequently than men do. The likelihood of using bikesharing is $8.7 \%$ higher among individuals with lower education levels than it is among those with higher education levels. Being a worker significantly increases the likelihood of using bikesharing by $17.2 \%$. Being able to drive raises a traveler's odds of using bikeshring by $50.3 \%$ but it shows a statistically significant negative effect on FBSU, which means that those who are able to drive have a $32.9 \%$ lower frequency of using bikesharing than non-drivers. When the household income level increases by one level, the likelihood that the respondent uses bikesharing decreases by $7.5 \%$. The number of vehicles in a household has a significant negative effect on PBSU and FBUS. On average, one additional household vehicle decreases a respondent's PBSU by $7.7 \%$ and FBUS by $11.5 \%$. It is not difficult to explain that having more household vehicles decreases individuals' frequency and probability of using bikesharing because they have more opportunities to drive their own vehicles. Generally, people who travel in spring and winter use bikesharing less frequently than those who travel in autumn. This result may be because people are not willing to ride bicycles in uncomfortably cold weather.

\subsection{Results Varying by Population Density}

ZINB models were also used to examine how the relationships between bikesharing and public transit vary by population density. Population density was divided into two groups: high population density (more than 2000 persons per square mile at the home location) and low population density (less than 2000 persons per square mile at the home location). The results were reported in Table 4 . The results show a significantly positively association between public transit usage and bikesharing ridership for the high population density group, but it was not statistically significant for the low population density group. For individuals living in an area of higher population density, a one-unit increase in public transit usage significantly increases a respondent's FBSU by $1.6 \%$, and the result is significant at the $0.05 \%$ level. This result suggests that this positive relationship between FPTU and FBSU is more pronounced in the high population density group. The FPTU is significantly positively associated with PBSU at the $0.001 \%$ level for both of the groups. One interesting observation is that among the high population density group, those who live in urban area show a $496.7 \%$ increase in the frequency of bikesharing usage. This may be explained by the higher bikesharing availability in urban areas with higher population density.

\subsection{Results Varying by Rail Service Status}

Table 5 shows how the associations between bikesharing and public transit vary by rail service status at the home location. If the area has rail service, a one-unit increase in public transit usage is positively associated with a $2.1 \%$ increase in bikesharing usage with significance at the $0.01 \%$ level. The relationship between FPTU and FBSU is not significant for those that are living in areas without rail service. This suggests that people may use bikesharing as a complement to rail ridership. The FPTU is significantly positively associated with PBSU at the $0.001 \%$ level for both groups. 
Table 4. Associations between bikesharing and public transit varying by population density.

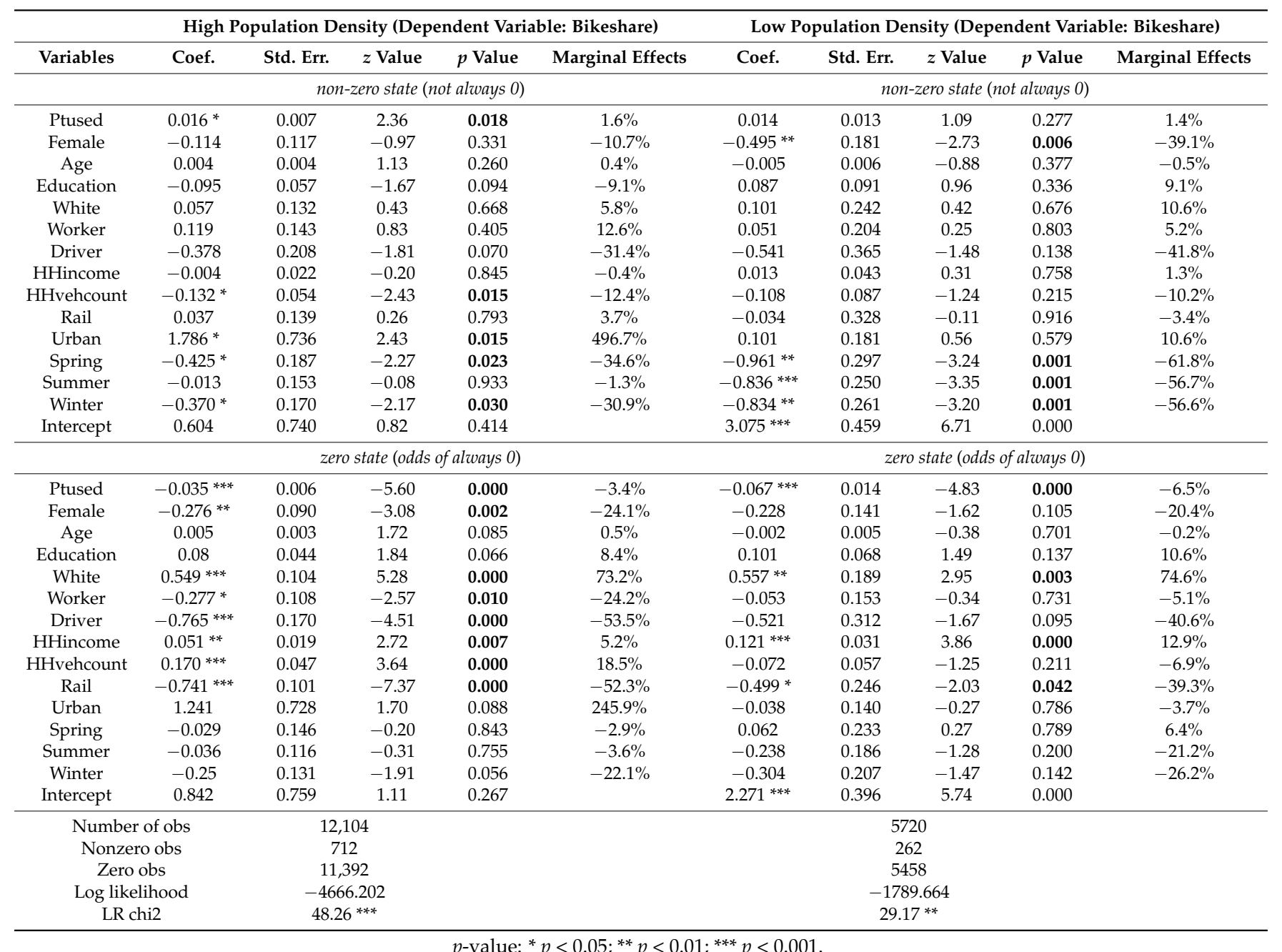

$p$-value: ${ }^{*} p<0.05 ;{ }^{* *} p<0.01 ; * * * p<0.001$. 
Table 5. Associations between bikesharing and public transit varying by rail service status.

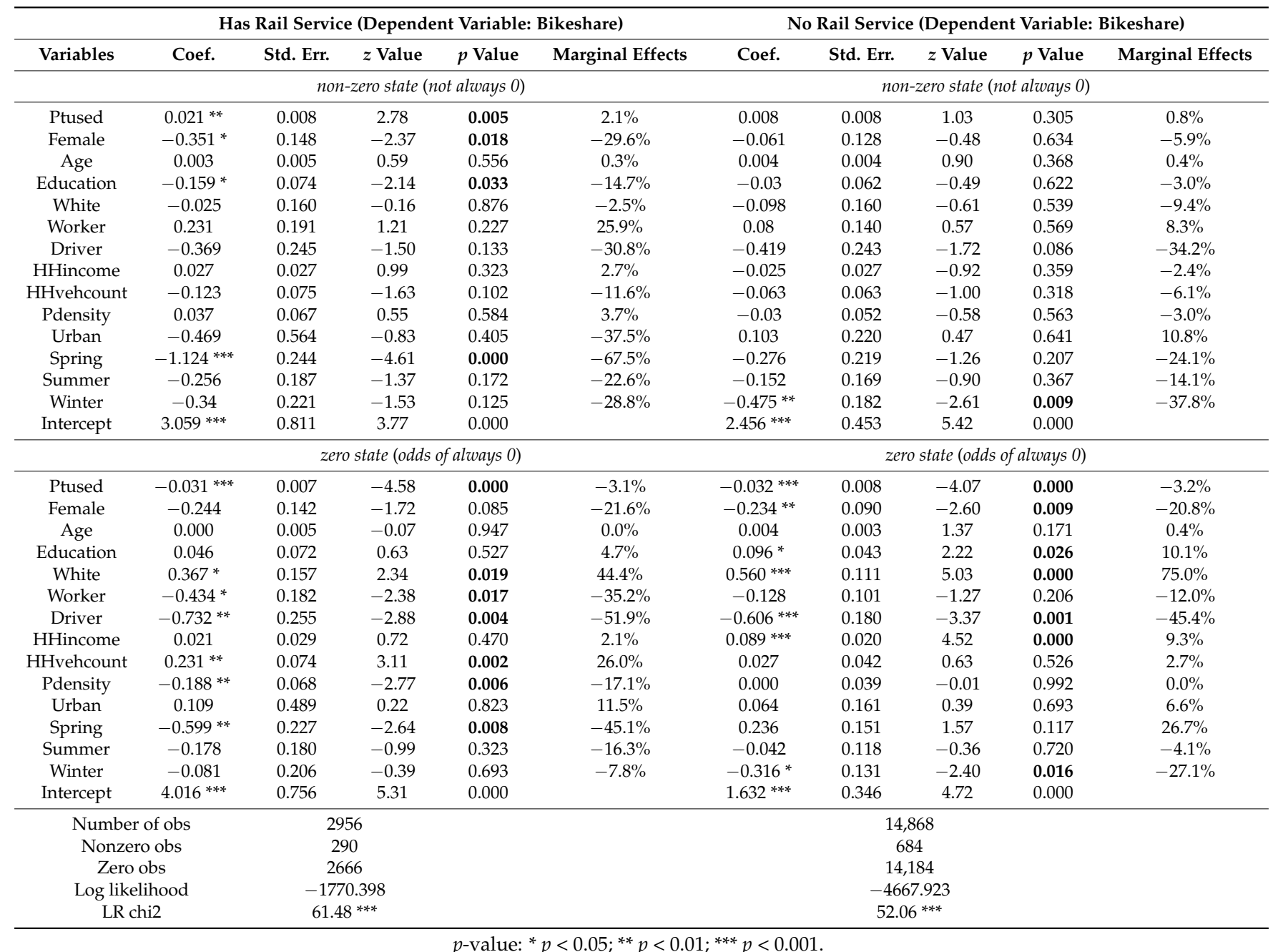

$p$-value: ${ }^{*} p<0.05 ;{ }^{* *} p<0.01 ; * * * p<0.001$. 


\section{Discussion}

This study examined the associations between bikesharing ridership and public transit usage. In general, our results show that a one-unit increase in public transit usage significantly increases a respondent's FBSU by $1.4 \%$ and PBSU by $4.0 \%$, indicating that FPTU is significantly positively associated with PBSU and FBSU, which means that individuals who use public transit more frequently are more likely to use bikesharing and to use it more frequently than those who use public transit less frequently. This finding may be explained by that bikesharing helps to solve first-mile/last-mile problems by connecting public transit stations with trip destinations. The positive relationship between these two modes was also found by other studies. Noland et al. [33] conducted a series of Bayesian regression models and they found that in New York City, bikesharing stations that are located near busy subway stations saw greater bikesharing usage. Ma et al. [32] examined the associations between rail station ridership and the annual ridership of bikesharing stations by conducting a regression analysis, and found that a $10 \%$ annual increase in annual bikesharing station ridership was significantly associated with a $2.8 \%$ increase in average daily weekday Metrorail station ridership.

There are also differences in the relationship between FPTU and FBSU by population density and rail service status: the significantly positive relationship between FPTU and FBSU is more pronounced among those living in areas with higher population density or with rail service, while this relationship is not significant among those that are living in areas with lower population density or without rail service. The results suggest that the associations between bikesharing and public transit may be different based on the regional environment. Access to bikesharing stations that are near public transit stops may explain these regional differences. Noland et al. [33] found that in New York City, bikesharing stations in areas with a higher population density saw more bikesharing usage. More urbanized areas have more residential population and more advanced infrastructures, providing greater opportunity to combine bikesharing systems with public transit systems $[32,33,35,36]$. Bikesharing may serve as first-mile, last-mile facilitators that provide access to and from public transit systems in these areas.

This evidence supports the positive relationship between bikesharing usage and public transit ridership. Some researchers also have pointed out that, even though public transit and bikesharing are substitutes in the short term, they could be complementary in the long term [56]. This finding of how public transit usage is associated with bikesharing behaviors is vital for future planning decisions and policies to facilitate the coordination of multimodal transportation. It is therefore important to develop strategies to connect these two transport modes to encourage bikesharing and public transit usage among the public as a whole.

\section{Conclusions}

Public bikesharing systems have rapidly expanded across many cities in the US. Bikesharing is recognized as an economic, efficient, healthy, and environment-friendly transport mode. Previous studies in the literature found that, in general, bikesharing is associated with public transit ridership. However, the interdependencies between public transit usage and bikesharing behaviors have been mixed and they have not been fully understood. In this study, we conducted ZINB models to examine the associations between public transit usage and monthly bikesharing ridership. Our results show that a one-unit increase in FPTU is significantly associated with a $4.0 \%$ increase in PBSU and a $1.4 \%$ increase in FBSU, which means that public transit usage is significantly positively associated with bikesharing usage. The significantly positive relationship between FPTU and FBSU is more pronounced among those living in areas with higher population density or with rail service.

This study provides significant empirical evidence for the formulation of interventions and policies targeting to promote integrated transportation systems that support multimodal transportation and mutually sustainable transport networks. The integration of biking systems and public transit systems has been shown to strengthen the advantages of both of these two transport modes [57,58]. Individuals who use public transit more frequently also have higher FBSU and PBSU. The empirical results demonstrate that public transit usage is significantly positively associated with bikesharing 
usage and suggest policy implications that improving public transit usage tends to increase the usage of bikesharing. Identifying strategies that facilitate bikesharing by improving public transportation accessibility could help to increase levels of bikesharing usage across the population as a whole.

There are some limitations to this study. First, bikesharing behaviors may also be affected by other factors, such as household bike ownership, personal attitudes, or perceptions of safety and convenience and with the 2017 NHTS dataset, we could not capture and control all of the factors that may affect individuals' bikesharing behaviors. Second, this study used the frequency of bikesharing usage in the last 30 days; hence, it does not reflect individuals' daily bikesharing behaviors or involve the trip purposes, trip distance, and travel time in each bikesharing trip, which should be an area of priority for future research to address.

Author Contributions: Yuanyuan Zhang contributed to conceptualization, formal analysis, methodology and manuscript writing of this study. Yuming Zhang contributed to project supervision. All authors reviewed the manuscript.

Acknowledgments: This research is supported by National Social Science Foundation of China (Grant No. 15ZDB157). The authors thank the anonymous reviewers and members of the editorial team for their constructive comments.

Conflicts of Interest: The authors declare no conflict of interest.

\section{References}

1. Shaheen, S.; Guzman, S.; Zhang, H. Bikesharing in Europe, the Americas, and Asia: Past, present, and future. Transp. Res. Rec. J. Transp. Res. Board 2010, 2143, 159-167. [CrossRef]

2. Fishman, E.; Washington, S.; Haworth, N. Bike share: A synthesis of the literature. Transp. Rev. 2013, 33, 148-165. [CrossRef]

3. Shaheen, S.A.; Martin, E.W.; Cohen, A.P.; Chan, N.D.; Pogodzinski, M. Public Bikesharing in North America during a Period of Rapid Expansion: Understanding Business Models, Industry Trends \& User Impacts; MTI Report; Mineta Transportation Institute Publications: San Jose, CA, USA, 2014; pp. 12-29.

4. Shaheen, S.; Cohen, A.; Martin, E. Public bikesharing in North America: Early operator understanding and emerging trends. Transp. Res. Rec. J. Transp. Res. Board 2013, 2387, 83-92. [CrossRef]

5. Fishman, E.; Washington, S.; Haworth, N. Bike share's impact on car use: Evidence from the United States, Great Britain, and Australia. Transp. Res. Part D Transp. Environ. 2014, 31, 13-20. [CrossRef]

6. Pelechrinis, K.; Zacharias, C.; Kokkodis, M.; Lappas, T. Economic impact and policy implications from urban shared transportation: The case of Pittsburgh's shared bike system. PLoS ONE 2017, 12, e0184092. [CrossRef] [PubMed]

7. Wang, M.; Zhou, X. Bike-sharing systems and congestion: Evidence from US cities. J. Transp. Geogr. 2017, 65, 147-154. [CrossRef]

8. Qiu, L.Y.; He, L.Y. Bike Sharing and the Economy, the Environment, and Health-Related Externalities. Sustainability 2018, 10, 1145. [CrossRef]

9. De Chardon, C.M.; Caruso, G. Estimating bike-share trips using station level data. Transp. Res. Part B Methodol. 2015, 78, 260-279. [CrossRef]

10. Biehl, A.; Ermagun, A.; Stathopoulos, A. Community mobility MAUP-ing: A socio-spatial investigation of bikeshare demand in Chicago. J. Transp. Geogr. 2018, 66, 80-90. [CrossRef]

11. Dell, M.; Iori, M.; Novellani, S.; Stützle, T. A destroy and repair algorithm for the bike sharing rebalancing problem. Comput. Oper. Res. 2016, 71, 149-162.

12. De Chardon, C.M.; Caruso, G.; Thomas, I. Bike-share rebalancing strategies, patterns, and purpose. J. Transp. Geogr. 2016, 55, 22-39. [CrossRef]

13. Regue, R.; Recker, W. Proactive vehicle routing with inferred demand to solve the bikesharing rebalancing problem. Transp. Res. Part E: Logist. Transp. Rev. 2014, 72, 192-209. [CrossRef]

14. Faghih-Imani, A.; Hampshire, R.; Marla, L.; Eluru, N. An empirical analysis of bike sharing usage and rebalancing: Evidence from Barcelona and Seville. Transp. Res. Part A Policy Pract. 2017, 97, 177-191. [CrossRef] 
15. Schuijbroek, J.; Hampshire, R.C.; Van Hoeve, W.J. Inventory rebalancing and vehicle routing in bike sharing systems. Eur. J. Oper. Res. 2017, 257, 992-1004. [CrossRef]

16. De Chardon, C.M.; Caruso, G.; Thomas, I. Bicycle sharing system 'success' determinants. Transp. Res. Part A Policy Pract. 2017, 100, 202-214. [CrossRef]

17. Sun, Y.; Mobasheri, A.; Hu, X.; Wang, W. Investigating impacts of environmental factors on the cycling behavior of bicycle-sharing users. Sustainability 2017, 6, 1060. [CrossRef]

18. Fishman, E.; Washington, S.; Haworth, N.; Watson, A. Factors influencing bike share membership: An analysis of Melbourne and Brisbane. Transp. Res. Part A Policy Pract. 2015, 71, 17-30. [CrossRef]

19. Fishman, E.; Washington, S.; Haworth, N.; Mazzei, A. Barriers to bikesharing: An analysis from Melbourne and Brisbane. J. Transp. Geogr. 2014, 41, 325-337. [CrossRef]

20. El-Assi, W.; Mahmoud, M.S.; Habib, K.N. Effects of built environment and weather on bike sharing demand: A station level analysis of commercial bike sharing in Toronto. Transportation 2017, 44, 589-613. [CrossRef]

21. Guo, Y.; Zhou, J.; Wu, Y.; Li, Z. Identifying the factors affecting bike-sharing usage and degree of satisfaction in Ningbo, China. PLoS ONE 2017, 12, e0185100. [CrossRef] [PubMed]

22. Kim, K. Investigation on the effects of weather and calendar events on bike-sharing according to the trip patterns of bike rentals of stations. J. Transp. Geogr. 2018, 66, 309-320. [CrossRef]

23. Martin, E.W.; Shaheen, S.A. Evaluating public transit modal shift dynamics in response to bikesharing: A tale of two US cities. J. Transp. Geogr. 2014, 41, 315-324. [CrossRef]

24. Campbell, K.B.; Brakewood, C. Sharing riders: How bikesharing impacts bus ridership in New York City. Transp. Res. Part A Policy Pract. 2017, 100, 264-282. [CrossRef]

25. Saberi, M.; Ghamami, M.; Gu, Y.; Shojaei, M.H.S.; Fishman, E. Understanding the impacts of a public transit disruption on bicycle sharing mobility patterns: A case of Tube strike in London. J. Transp. Geogr. 2018, 66, 154-166. [CrossRef]

26. NACTO. Bike Share in the US: 2010-2016. 2016. Available online: https:/ /nacto.org/bike-share-statistics2016/ (accessed on 22 April 2018).

27. Ricci, M. Bike sharing: A review of evidence on impacts and processes of implementation and operation. Res. Transp. Bus. Manag. 2015, 15, 28-38. [CrossRef]

28. Hampshire, R.C.; Marla, L. An analysis of bike sharing usage: Explaining trip generation and attraction from observed demand. In Proceedings of the 91st Annual Meeting of the Transportation Research Board, Washington, DC, USA, 22-26 January 2012. No. 12-2099.

29. Nair, R.; Miller-Hooks, E.; Hampshire, R.C.; Bušić, A. Large-scale vehicle sharing systems: Analysis of Vélib'. Int. J. Sustain. Transp. 2013, 7, 85-106. [CrossRef]

30. Rixey, R. Station-level forecasting of bikesharing ridership: Station Network Effects in Three US Systems. Transp. Res. Rec. J. Transp. Res. Board 2013, 2387, 46-55. [CrossRef]

31. Sato, H.; Miwa, T.; Morikawa, T. A study on use and location of community cycle stations. Res. Transp. Econ. 2015, 53, 13-19. [CrossRef]

32. Ma, T.; Liu, C.; Erdoğan, S. Bicycle sharing and public transit: Does Capital Bikeshare affect Metrorail ridership in Washington, DC? Transp. Res. Rec. J. Transp. Res. Board 2015, 2534, 1-9. [CrossRef]

33. Noland, R.B.; Smart, M.J.; Guo, Z. Bikeshare trip generation in New York city. Transp. Res. Part A Policy Pract. 2016, 94, 164-181. [CrossRef]

34. Lansell, K. Melbourne Bike Share and Public Transport Integration; University of Melbourne: Melbourne, Australia, 2011.

35. Tingting, L.; Li, L.; Wei, L. Analysis of public bicycles' impact on residents' trip chain. In Proceedings of the 2011 International Conference on IEEE Transportation, Mechanical, and Electrical Engineering (TMEE), Changchun, China, 16-18 December 2011; pp. 182-185.

36. Tang, Y.; Pan, H.; Shen, Q. Bike-sharing systems in Beijing, Shanghai, and Hangzhou and their impact on travel behavior. In Proceedings of the Transportation Research Board 90th Annual Meeting, Washington, DC, USA, 23-27 January 2011; No. 11-3862.

37. Shaheen, S.; Zhang, H.; Martin, E.; Guzman, S. China's Hangzhou public bicycle: Understanding early adoption and behavioral response to bikesharing. Transp. Res. Rec. J. Transp. Res. Board 2011, 2247, $33-41$. [CrossRef]

38. Shaheen, S.; Martin, E.; Cohen, A. Public bikesharing and modal shift behavior: A comparative study of early bikesharing systems in North America. Int. J. Transp. 2013, 1, 35-54. [CrossRef] 
39. Buck, D.; Buehler, R.; Happ, P.; Rawls, B.; Chung, P.; Borecki, N. Are bikeshare users different from regular cyclists? A first look at short-term users, annual members, and area cyclists in the Washington, DC, region. Transp. Res. Rec. J. Transp. Res. Board 2013, 2387, 112-119. [CrossRef]

40. Fuller, D.; Gauvin, L.; Kestens, Y.; Morency, P.; Drouin, L. The potential modal shift and health benefits of implementing a public bicycle share program in Montreal, Canada. Int. J. Behave. Nutr. Phys. Act. 2013, 10, 66. [CrossRef] [PubMed]

41. Murphy, E.; Usher, J. The role of bicycle-sharing in the city: Analysis of the Irish experience. Int. J. Sustain. Transp. 2015, 9, 116-125. [CrossRef]

42. Transport for London. Travel in London Report 3; Transport for London: London, UK, 2010. Available online: http:/ / content.tfl.gov.uk/travel-in-london-report-3.pdf (accessed on 16 March 2018).

43. Webster, K.M.; Cunningham, C.J. Preparing for bike-sharing: Insight from focus groups and surveys, Chattanooga, Tennessee, 2010. Health Promo. Pract. 2013, 14, 62-68. [CrossRef] [PubMed]

44. U.S. Department of Transportation. Federal Highway Administration, 2017 National Household Travel Survey. Available online: http:/ /nhts.ornl.gov (accessed on 11 March 2018).

45. Zuur, A.F.; Ieno, E.N.; Walker, N.J.; Saveliev, A.A.; Smith, G.M. Zero-truncated and zero-inflated models for count data. In Mixed Effects Models and Extensions in Ecology with R; Springer: New York, NY, USA, 2009; pp. 261-293.

46. Cameron, A.C.; Trivedi, P.K. Regression Analysis of Count Data (Vol. 53); Cambridge University Press: Cambridge, UK, 2013.

47. Ver Hoef, J.M.; Boveng, P.L. Quasi-poisson Vs. Negative Binomial Regression: How Should We Model Overdispersed Count Data? Ecology 2007, 88, 2766-2772. [CrossRef] [PubMed]

48. Lord, D.; Mannering, F. The statistical analysis of crash-frequency data: A review and assessment of methodological alternatives. Transp. Res. Part A Policy Pract. 2010, 44, 291-305. [CrossRef]

49. Ridout, M.; Hinde, J.; DeméAtrio, C.G. A score test for testing a zero-inflated Poisson regression model against zero-inflated negative binomial alternatives. Biometrics 2001, 57, 219-223. [CrossRef] [PubMed]

50. Washington, S.P.; Karlaftis, M.G.; Mannering, F. Statistical and Econometric Methods for Transportation Data Analysis; CRC Press: Boca Raton, FL, USA, 2010.

51. Dong, C.; Clarke, D.B.; Yan, X.; Khattak, A.; Huang, B. Multivariate random-parameters zero-inflated negative binomial regression model: An application to estimate crash frequencies at intersections. Accid. Anal. Prev. 2014, 70, 320-329. [CrossRef] [PubMed]

52. Shen, S.; Neyens, D.M. Factors affecting teen drivers' crash-related length of stay in the hospital. J. Transp. Health 2017, 4, 162-170. [CrossRef]

53. Greene, W.H. Accounting for Excess Zeros and Sample Selection in Poisson and Negative Binomial Regression Models; NYU Working Paper No. EC-94-10; New York University: New York, NY, USA, 1994.

54. Fang, R.; Wagner, B.D.; Harris, J.K.; Fillon, S.A. Zero-inflated negative binomial mixed model: An application to two microbial organisms important in oesophagitis. Epidemiol. Infect. 2016, 144, 2447-2455. [CrossRef] [PubMed]

55. Yau, K.K.; Wang, K.; Lee, A.H. Zero-inflated negative binomial mixed regression modeling of over-dispersed count data with extra zeros. Biometr. J. 2003, 45, 437-452. [CrossRef]

56. Singleton, P.; Clifton, K. Exploring synergy in bicycle and transit use: Empirical evidence at two scales. Transp. Res. Rec. J. Transp. Res. Board 2014, 2417, 92-102. [CrossRef]

57. Brons, M.; Givoni, M.; Rietveld, P. Access to railway stations and its potential in increasing rail use. Transp. Res. Part A Policy Pract. 2009, 43, 136-149. [CrossRef]

58. Pucher, J.; Buehler, R. City Cycling; MIT Press: Cambridge, MA, USA, 2012.

(C) 2018 by the authors. Licensee MDPI, Basel, Switzerland. This article is an open access article distributed under the terms and conditions of the Creative Commons Attribution (CC BY) license (http:/ / creativecommons.org/licenses/by/4.0/). 